\title{
Endovascular Aortic Repair Increases Vascular Stiffness and Alters Cardiac Structure and Function
}

\author{
Yasuharu Takeda, MD; Yasushi Sakata, MD; Tomohito Ohtani, MD; Shunsuke Tamaki, MD; \\ Yosuke Omori, MD; Yasumasa Tsukamoto, MD; Yoshihiro Aizawa, MD; \\ Kazuo Shimamura, MD; Yukitoshi Shirakawa, MD; Toru Kuratani, MD; Yoshiki Sawa, MD; \\ Kazuhiro Yamamoto, MD; Toshiaki Mano, MD; Issei Komuro, MD
}

\begin{abstract}
Background: Endovascular aortic repair (EVAR) is performed in patients with thoracic or abdominal aortic aneurysm because it is less invasive than conventional open repair. However, the effects of EVAR on vascular and cardiac function remain to be clarified.

Methods and Results: We studied the effects of EVAR on several outcome variables in 40 consecutive patients undergoing EVAR for abdominal and/or thoracic aneurysm with preserved ejection fraction. Echocardiography and brachial-ankle pulse wave velocity (baPWV) data were collected before, 1 week, and 1 year after EVAR. Although no changes in blood pressure were found, baPWV, left ventricular mass index (LVMI), and left atrial volume index were significantly elevated at both post-op time periods after EVAR compared with baseline data. The changes in LVMI correlated with those in baPWV $(R=0.32, P<0.05)$. Among the 22 patients who were successfully followed up, 13 showed deterioration in exercise tolerance 1 year after EVAR. Diastolic wall strain, an index for LV distensibility, was lower at baseline in patients with worsening exercise tolerance than in those with unchanged tolerance.
\end{abstract}

Conclusions: EVAR increased vascular stiffness and induced LV hypertrophy and diastolic dysfunction without a corresponding elevation of blood pressure in the acute and chronic phases. In addition, low LV distensibility at baseline was associated with the impairment of exercise tolerance. EVAR-induced stiffness of arteries leads to limited clinical symptoms. (Circ $J$ 2014; 78: 322-328)

Key Words: Endovascular aortic repair; Left ventricular diastolic function; Vascular stiffness

$\mathbf{E}$ ndovascular aortic repair (EVAR), which involves inserting a fabric tube supported by a metal framework through a catheter into a weakened artery, is widely performed in patients with thoracic (TAA), thoraco-abdominal (TAAA), or abdominal aortic aneurysm (AAA) because it is less invasive than conventional open repair and improves postoperative quality of life., ${ }^{1,2}$ However, recent trials have reported that, although EVAR may provide an early survival advantage over conventional open repair, ${ }^{3}$ the rate of overall survival is similar for the 2 procedures over longer follow-up periods. ${ }^{4,5}$ EVAR patients in those trials had a lower rate of aneurysmrelated death in the first 2 years compared with conventional treatment, but overall survival was reduced through deaths from other causes.

\section{Editorial p 307}

The failure of EVAR to provide a long-term survival benefit over conventional open repair may be because the prognosis of aortic aneurysm patients is at least partially determined by the presence of other cardiovascular diseases. For example, in the trial comparing 2-year outcomes of patients receiving treatment for AAAs, a number of deaths from congestive heart failure were documented only in the EVAR group. ${ }^{4}$ In addition, several studies have shown that vascular compliance in AAA patients is increased by EVAR at the level of the aneurysmal sac. ${ }^{6-8}$ The heart typically adapts in response to higher systolic loads by both hypertrophy and ventricular systolic stiffening, leading to altered coupling between the heart and vessels, which severely affects cardiovascular reserve function. In consider-

Received July 8, 2013; revised manuscript received September 30, 2013; accepted October 10, 2013; released online November 29, 2013 Time for primary review: 22 days

Departments of Cardiovascular Medicine (Y. Takeda, Y. Sakata, T.O., S.T., Y.O., Y. Tsukamoto, Y.A., K.Y., T.M., I.K.), Cardiovascular Surgery (K.S., Y. Shirakawa, T.K., Y. Sawa), Osaka University Graduate School of Medicine, Suita; Division of Cardiovascular Medicine, Department of Molecular Medicine and Therapeutics, Faculty of Medicine, Tottori University, Yonago (K.Y.), Japan

Mailing address: Yasushi Sakata, MD, PhD, FACC, Department of Cardiovascular Medicine, Osaka University Graduate School of Medicine, 2-2 Yamadaoka, Suita 565-0871, Japan. E-mail: yasushisk@ cardiology.med.osaka-u.ac.jp

ISSN-1346-9843 doi:10.1253/circj.CJ-13-0877

All rights are reserved to the Japanese Circulation Society. For permissions, please e-mail: cj@j-circ.or.jp 
ing this left ventricular (LV)-arterial interaction, ${ }^{9,10}$ the effects of EVAR on vascular stiffness and LV performance need to be clarified.

In the present retrospective study, we evaluated the early and long-term outcomes of consecutive patients who underwent EVAR at our single center in Japan to clarify the effects of this procedure on vascular and cardiac function, cardiac geometry, and exercise tolerance.

\section{Methods}

\section{Study Subjects and Protocols}

This retrospective study was approved by the Ethics Committee of Osaka University Hospital. We enrolled 40 consecutive Japanese patients (8 TAA cases, 2 TAAA cases, 30 AAA cases) who underwent EVAR between August 2008 and February 2010 at Osaka University Hospital and who met the following inclusion criteria: (1) without history of graft replacement, surgical stent grafting or endovascular stent grafting of the aorta, (2) without aortic dissection, (3) echocardiographic confirmation of ejection fraction (EF) $\geq 50 \%$, (4) no significant valve, lung, or congenital heart diseases, (5) without significant coronary stenosis evaluated by coronary arteriography or coronary computed tomography angiography, (6) without LV regional wall motion abnormality, (7) without atrial fibrillation, hepatic cirrhosis, or history of open-heart operation, (8) without chronic renal failure on hemodialysis, and (9) without arteriosclerosis obliterans evaluated by computed tomography angiography and an ankle pressure index $<0.9$. Medical records were reviewed by cardiologists to assess patient characteristics, which are summarized in Table $\mathbf{1 .}$

Echocardiographic data were collected before (pre-op), 1 week after (post-op), and 1 year (follow-up) after EVAR. At the time of echocardiography, the height and body weight of each participant were measured and body mass index (BMI) was calculated. The glomerular filtration rate was estimated using an equation modified for the Japanese. ${ }^{11}$ Brachial-ankle pulse wave velocity (baPWV) was measured using a noninvasive automatic waveform analyzer (model BP-203RPE II; Omron Healthcare Co, Ltd, Kyoto, Japan) ${ }^{12}$ at pre-op, post-op, and follow-up. In addition, all of the patients' symptoms were assessed using a specific activity scale (SAS) questionnaire at pre-op and follow-up, and were asked to report on their history of diabetes mellitus, hypertension, and dyslipidemia at pre-op, as previously described. ${ }^{13}$ Medications were not withheld before this study for ethical reasons.

To clarify the factors affecting exercise tolerance in patients undergoing EVAR, baseline characteristic data were compared between patients with worsening SAS scores at follow-up (worsening exercise tolerance group, $\mathrm{n}=13$ ) and those with unchanged scores (unchanged exercise tolerance group, $n=9$ ).

\section{Echocardiography}

Echocardiograms and Doppler ultrasound recordings were obtained for each patient using commercially available echocardiographic machines, as previously described. ${ }^{13} \mathrm{EF}$, relative wall thickness, and LV mass were then calculated as previously described. ${ }^{13}$ LV mass index (LVMI) was adjusted for height with the Devereux formula (the ratio of LV mass to height ${ }^{2.7}$ ). ${ }^{14}$ LV volume ${ }^{15}$ and left atrial (LA) volume ${ }^{16}$ were calculated using the bi-apical (2- and 4-chamber views) Simpson's rule. LV volume index and LA volume index (LAVI) were adjusted for height with the Devereux formula (the ratio of LV volume to height ${ }^{2.7}$ and the ratio of LA volume to height $\left.{ }^{2.7}\right) .{ }^{14}$ Tissue Doppler imaging of the mitral annulus level was performed at

\begin{tabular}{|c|c|}
\hline Characteristic & $\begin{array}{l}\text { All patients } \\
(n=40)\end{array}$ \\
\hline Age (years) & $72 \pm 7$ \\
\hline Male (\%) & 73 \\
\hline $\mathrm{BMI}\left(\mathrm{kg} / \mathrm{m}^{2}\right)$ & $23.0 \pm 2.7$ \\
\hline TAA (\%) & 20 \\
\hline TAAA (\%) & 5 \\
\hline AAA $(\%)$ & 75 \\
\hline Length of stent graft $(\mathrm{cm})$ & $16.6 \pm 3.9$ \\
\hline Type II diabetes mellitus (\%) & 10 \\
\hline Hypertension (\%) & 80 \\
\hline Dyslipidemia (\%) & 33 \\
\hline Previous $\mathrm{PCl}(\%)$ & 15 \\
\hline Previous CABG (\%) & 0 \\
\hline eGFR $\left(\mathrm{ml} \cdot \mathrm{min}^{-1} \cdot 1.73 \mathrm{~m}^{-2}\right)$ & $68 \pm 19$ \\
\hline $\mathrm{Hb}(\mathrm{g} / \mathrm{dl})$ & $13.2 \pm 1.7$ \\
\hline \multicolumn{2}{|l|}{ Medications } \\
\hline Angiotensin-converting enzyme inhibitors (\%) & 10 \\
\hline Angiotensin II receptor blockers (\%) & 33 \\
\hline$\beta$-blockers (\%) & 12.5 \\
\hline Calcium-channel blockers (\%) & 70 \\
\hline Diuretics (\%) & 5 \\
\hline Statins (\%) & 35 \\
\hline Insulin (\%) & 2.5 \\
\hline$a$-glucosidase inhibitors (\%) & 0 \\
\hline Antiplatelet drugs & 30 \\
\hline
\end{tabular}

AAA, abdominal aortic aneurysm; BMI, body mass index; CABG, coronary artery bypass grafting; eGFR, estimated glomerular filtration rate; $\mathrm{Hb}$, hemoglobin; $\mathrm{PCl}$, percutaneous coronary intervention; TAA, thoracic aortic aneurysm; TAAA, thoraco-abdominal aortic aneurysm.

the septal position to measure early (E') and late (A') diastolic myocardial velocities, as previously described. ${ }^{13}$

We recently reported that diastolic wall strain (DWS; [LV posterior wall thickness at end-systole - LV posterior wall thickness at end-diastole]/LV posterior wall thickness at endsystole) theoretically reflects LV distensibility according to the linear elastic theory and is inversely correlated with myocardial stiffness constant in a rat model of heart failure with preserved EF. ${ }^{17}$ Thus, DWS was used in the present study as an index of LV compliance.

\section{Statistical Analysis}

Results are expressed as the mean \pm SD. Differences between outcome variables measured at pre-op, post-op, and follow-up were assessed using the paired Student's t-test. Differences between groups were assessed using the unpaired Student's t-test. The correlation between 2 indices was assessed using linear regression analysis with the least-squares method. All statistical analyses were performed using commercially available statistical software (JMP version 8.02, SAS Institute Inc, Cary, NC, USA). $\mathrm{P}<0.05$ was considered statistically significant.

\section{Results}

\section{Patients' Characteristics and Data Collected Pre- and Post- Op}

Post-op data were collected from 40 patients $7.1 \pm 2.4$ days after 


\begin{tabular}{|c|c|c|c|}
\hline Characteristic & Pre-op $(n=40)$ & Post-op $(n=40)$ & $P$ value \\
\hline Systolic blood pressure (mmHg) & $131 \pm 15$ & $128 \pm 15$ & 0.075 \\
\hline Diastolic blood pressure $(\mathrm{mmHg})$ & $76 \pm 8$ & $72 \pm 9$ & $<0.05$ \\
\hline Heart rate (beats/min) & $65 \pm 10$ & $69 \pm 12$ & $<0.05$ \\
\hline baPWV $(\mathrm{cm} / \mathrm{s})$ & $1,914 \pm 389$ & $2,096 \pm 459$ & $<0.05$ \\
\hline Inferior vena cava dimension (mm) & $12 \pm 3$ & $12 \pm 3$ & 0.574 \\
\hline LV volume index at end-diastole $\left(\mathrm{ml} / \mathrm{m}^{2.7}\right)$ & $28.3 \pm 4.9$ & $29.1 \pm 4.0$ & 0.096 \\
\hline Left atrial volume index $\left(\mathrm{ml} / \mathrm{m}^{2.7}\right)$ & $13.7 \pm 4.4$ & $15.4 \pm 4.6$ & $<0.05$ \\
\hline LVEF (\%) & $68 \pm 5$ & $67 \pm 4$ & 0.127 \\
\hline IVST at end-diastole (mm) & $9.0 \pm 2.3$ & $9.1 \pm 2.3$ & 0.623 \\
\hline LV PWT at end-diastole (mm) & $8.7 \pm 1.1$ & $8.9 \pm 0.9$ & 0.118 \\
\hline LV PWT at end-systole (mm) & $15.0 \pm 2.0$ & $15.1 \pm 2.1$ & 0.749 \\
\hline DWS & $0.41 \pm 0.09$ & $0.40 \pm 0.09$ & 0.429 \\
\hline LV mass index $\left(\mathrm{g} / \mathrm{m}^{2.7}\right)$ & $42 \pm 10$ & $45 \pm 11$ & $<0.05$ \\
\hline Relative wall thickness & $0.35 \pm 0.05$ & $0.35 \pm 0.04$ & 0.663 \\
\hline E/A ratio & $7.8 \pm 1.3$ & $0.78 \pm 0.20$ & 0.427 \\
\hline Deceleration time of $E$ wave (ms) & $244 \pm 37$ & $243 \pm 39$ & 0.886 \\
\hline$E^{\prime}(\mathrm{cm} / \mathrm{s})$ & $7.8 \pm 1.3$ & $7.8 \pm 1.5$ & 0.773 \\
\hline E/E' ratio & $8.2 \pm 1.8$ & $8.4 \pm 1.5$ & 0.385 \\
\hline
\end{tabular}

Values are expressed as the mean \pm SD.

A, peak velocity of transmitral flow velocity curve at atrial contraction; baPWV, brachial-ankle pulse wave velocity; DWS, diastolic wall strain; E, peak early diastolic flow velocity of transmitral flow velocity curve; E', peak early diastolic velocity of the tissue Doppler imaging of the mitral annulus movement at septal position; EF, ejection fraction; IVST, interventricular septal thickness; LV, left ventricular; PWT, posterior wall thickness.

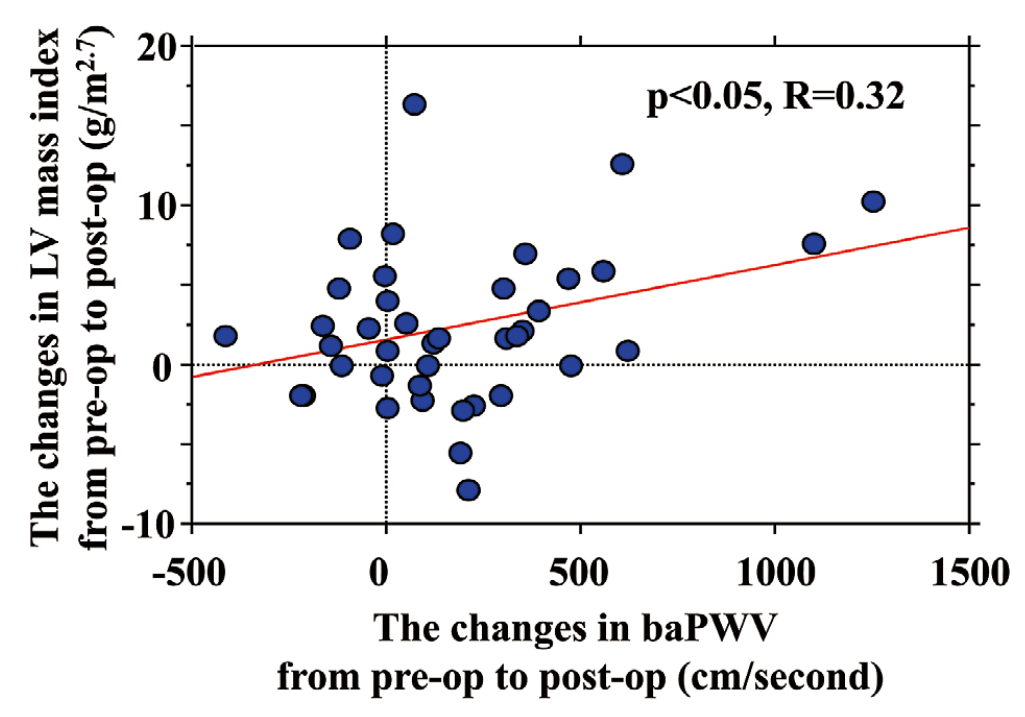

Figure 1. Relationship between changes in left ventricular (LV) mass index from pre-op to post-op and those in brachial-ankle pulse wave velocity (baPWV). As shown by the trendline, the changes in LV mass index positively correlated with those in baPWV.

EVAR. The background characteristics, and hemodynamic and echocardiographic data of the study subjects $(n=40)$ at pre-op and post-op are presented in Table 2. Comparison of the data revealed that heart rate (HR) was higher at post-op than at pre-op, although the difference was only 4 beats/min. EVAR did not affect systolic blood pressure (BP), but diastolic BP was lower at post-op than at pre-op. In spite of these minimal changes in HR and BP, baPWV was significantly elevated after the grafting procedure. There was no difference in the degree of baPWV between cases of AAA and the others. LVMI was significantly increased at post-op compared with pre-op, and the increase in LVMI positively correlated with that in baPWV
$(\mathrm{R}=0.32, \mathrm{P}<0.05$; Figure 1). In addition, LAVI was larger at post-op than at pre-op. No differences in any of the other outcome variables were detected between pre- and post-op.

\section{Long-Term Effects of EVAR}

At the time of follow-up, 18 patients were excluded from the analysis because they required an additional intervention, which included coronary intervention, coil embolization of endoleaks following EVAR, and EVAR, or because the follow-up examination was performed at another hospital. Therefore, follow-up data was collected for 22 patients approximately 1 year (379.9 \pm 157.3 days) after EVAR. The background char- 
Table 3. Baseline (Pre-Op) Characteristics of Patients and 1-Year (Follow-up) Outcomes After Endovascular Aortic Repair

Characteristic

Specific activity scale score

Systolic blood pressure $(\mathrm{mmHg})$

Diastolic blood pressure $(\mathrm{mmHg})$

Heart rate (beats/min)

baPWV $(\mathrm{cm} / \mathrm{s})$

Inferior vena cava dimension $(\mathrm{mm})$

$\mathrm{LV}$ volume index at end-diastole $\left(\mathrm{ml} / \mathrm{m}^{2.7}\right)$

Left atrial volume index $\left(\mathrm{ml} / \mathrm{m}^{2.7}\right)$

LVEF (\%)

IVST at end-diastole $(\mathrm{mm})$

LV PWT at end-diastole $(\mathrm{mm})$

LV PWT at end-systole $(\mathrm{mm})$

DWS

LV mass index $\left(\mathrm{g} / \mathrm{m}^{2.7}\right)$

Relative wall thickness

E/A ratio

Deceleration time of $E$ wave (ms)

$\mathrm{E}^{\prime}(\mathrm{cm} / \mathrm{s})$

E/E' ratio

Serum creatinine $(\mathrm{mg} / \mathrm{dl})$

eGFR $\left(\mathrm{ml} \cdot \mathrm{min}^{-1} \cdot 1.73 \mathrm{~m}^{-2}\right)$

Abbreviations as in Tables 1,2.

\begin{tabular}{|c|c|c|c|}
\hline Characteristic & $\begin{array}{l}\text { Unchanged }(n=9) \\
\text { Exercise tolerance }\end{array}$ & $\begin{array}{l}\text { Worsening }(n=13) \\
\text { Exercise tolerance }\end{array}$ & $P$ value \\
\hline Age (years) & $69 \pm 2$ & $72 \pm 2$ & 0.321 \\
\hline Length of stent graft (cm) & $16.4 \pm 2.1$ & $16.9 \pm 2.9$ & 0.669 \\
\hline \multicolumn{4}{|l|}{ Data collected pre-op } \\
\hline Specific activity scale score & $5.9 \pm 1.5$ & $6.0 \pm 1.7$ & 0.875 \\
\hline $\mathrm{BMI}\left(\mathrm{kg} / \mathrm{m}^{2}\right)$ & $23.1 \pm 2.1$ & $22.9 \pm 3.2$ & 0.931 \\
\hline Systolic blood pressure $(\mathrm{mmHg})$ & $131 \pm 17$ & $132 \pm 14$ & 0.918 \\
\hline Heart rate (beats/min) & $62 \pm 11$ & $65 \pm 8$ & 0.442 \\
\hline baPWV (cm/s) & $1,837 \pm 458$ & $1,832 \pm 222$ & 0.974 \\
\hline LV volume index at end-diastole $\left(\mathrm{ml} / \mathrm{m}^{2.7}\right)$ & $30.0 \pm 4.1$ & $28.7 \pm 5.3$ & 0.568 \\
\hline Left atrial volume index $\left(\mathrm{ml} / \mathrm{m}^{2.7}\right)$ & $16.2 \pm 1.7$ & $12.4 \pm 1.5$ & 0.105 \\
\hline LVEF (\%) & $68 \pm 6$ & $67 \pm 5$ & 0.793 \\
\hline IVST at end-diastole (mm) & $10.1 \pm 3.9$ & $9.0 \pm 1.1$ & 0.332 \\
\hline LV PWT at end-diastole (mm) & $8.1 \pm 0.9$ & $9.0 \pm 1.0$ & $<0.05$ \\
\hline LV PWT at end-systole $(\mathrm{mm})$ & $15.4 \pm 2.0$ & $14.8 \pm 1.5$ & 0.374 \\
\hline LV mass index $\left(\mathrm{g} / \mathrm{m}^{2.7}\right)$ & $43 \pm 11$ & $43 \pm 12$ & 0.940 \\
\hline Relative wall thickness & $0.33 \pm 0.05$ & $0.37 \pm 0.04$ & 0.059 \\
\hline E/A ratio & $0.84 \pm 0.27$ & $0.80 \pm 0.16$ & 0.737 \\
\hline Deceleration time of $E$ wave (ms) & $234 \pm 27$ & $260 \pm 32$ & 0.059 \\
\hline$E^{\prime}(\mathrm{cm} / \mathrm{s})$ & $7.4 \pm 1.5$ & $8.0 \pm 1.4$ & 0.363 \\
\hline E/E' ratio & $8.1 \pm 2.2$ & $8.8 \pm 1.3$ & 0.315 \\
\hline eGFR (ml-min.1.73 $\left.\mathrm{m}^{2}\right)$ & $69 \pm 23$ & $66 \pm 15$ & 0.668 \\
\hline $\mathrm{Hb}(\mathrm{mg} / \mathrm{dl})$ & $14.2 \pm 1.4$ & $13.2 \pm 1.6$ & 0.142 \\
\hline
\end{tabular}

Values are expressed as the mean \pm SD.

BMI, body mass index. Other abbreviations as in Tables 1.2.

$\begin{array}{ccc}\text { Pre-op }(\mathbf{n}=\mathbf{2 2}) & \text { Follow-up }(\mathbf{n}=\mathbf{2 2}) & \text { P value } \\ 6.0 \pm 1.6 & 5.3 \pm 1.9 & <0.05 \\ 131 \pm 15 & 131 \pm 16 & 0.953 \\ 75 \pm 8 & 74 \pm 10 & 0.476 \\ 64 \pm 9 & 62 \pm 10 & 0.283 \\ 1,834 \pm 329 & 1,942 \pm 387 & <0.05 \\ 12 \pm 3 & 12 \pm 2 & 0.606 \\ 29.2 \pm 4.8 & 27.2 \pm 4.4 & <0.05 \\ 14.0 \pm 5.3 & 16.2 \pm 4.7 & <0.05 \\ 68 \pm 5 & 68 \pm 5 & 0.866 \\ 9.5 \pm 2.6 & 9.8 \pm 2.8 & 0.088 \\ 8.6 \pm 1.0 & 9.0 \pm 1.0 & 0.201 \\ 15.0 \pm 1.7 & 14.8 \pm 2.4 & 0.646 \\ 0.42 \pm 0.09 & 0.38 \pm 0.10 & 0.066 \\ 43 \pm 11 & 45 \pm 11 & <0.05 \\ 0.35 \pm 0.05 & 0.37 \pm 0.04 & <0.05 \\ 0.82 \pm 0.21 & 0.75 \pm 0.19 & <0.05 \\ 249 \pm 32 & 246 \pm 47 & 0.733 \\ 7.8 \pm 1.5 & 7.3 \pm 1.8 & 0.060 \\ 8.5 \pm 1.7 & 8.6 \pm 2.1 & 0.052 \\ 0.88 \pm 0.34 & 1.04 \pm 0.68 & <0.05 \\ 13.6 \pm 1.6 & 13.5 \pm 1.8 & 0.766\end{array}$



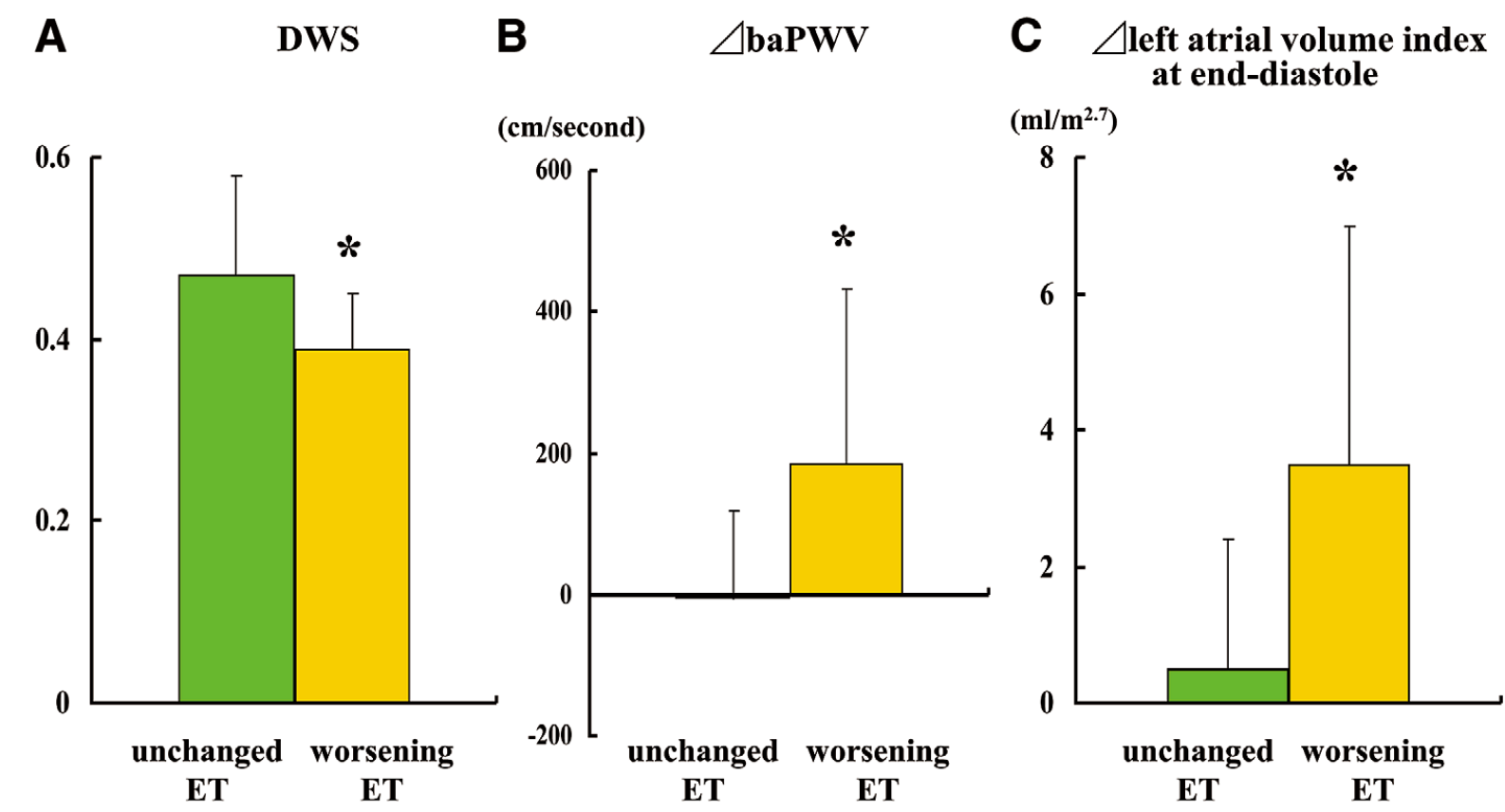

Figure 2. Comparison of patients' baseline characteristics based on 1-year (follow-up) exercise tolerance. DWS (pre-op) (A), and the increase in baPWV (B) and left atrial volume index (LAVI) (C) from pre-op to follow-up in the worsening and unchanged exercise tolerance $(E T)$ groups. The upper horizontal bars indicate SD. *Significant difference $(P<0.05)$ between the unchanged and worsening ET groups. baPWV, brachial-ankle pulse wave velocity; DWS, diastolic wall strain; LAVI, left atrial volume index

acteristics, and hemodynamic and echocardiographic data of the 22 patients at pre-op and follow-up are presented in Table 3. No patients required hospitalization for acute decompensated heart failure. However, 13 of 22 patients had lower SAS scores at follow-up as compared with pre-op. Although systolic BP and HR were not elevated, baPWV was significantly higher at follow-up than at pre-op. LVMI, LAVI and relative wall thickness were significantly larger $(\mathrm{P}<0.05)$, and the $\mathrm{E} / \mathrm{A}$ ratio was significantly lower at follow-up than at pre-op $(\mathrm{P}<0.05)$. E' and DWS at follow-up tended to be low compared with the pre-op values, although the difference was not statistically significant. No differences in any of the other outcome variables were detected between pre- and post-op.

\section{Effects of EVAR on Exercise Tolerance}

Data collected for the worsening and unchanged exercise tolerance groups at pre-op are presented in Table 4. DWS at preop was significantly lower in the worsening exercise tolerance group compared with the unchanged exercise tolerance group (Figure 2A). In addition, increases in baPWV and LAVI from pre-op to follow-up were detected only for the worsening exercise tolerance group (Figures $\mathbf{2 B}, \mathbf{C}$ ). No differences in any of the other outcome variables were detected between the 2 groups.

\section{Discussion}

EVAR is being performed in a growing number of patients with TAA, TAAA, or AAA because it is less invasive than conventional open repair; however, prognosis is not always improved. The present study has demonstrated for the first time that EVAR increases vascular stiffness and induces LV hypertrophy and
LA enlargement without elevating BP in the short-term postoperative period. Notably, these unfavorable outcomes persisted until at least 1 year after the procedure. LA enlargement was associated with deterioration of E' velocity and DWS at followup and likely resulted from deterioration of diastolic function. ${ }^{18}$ In patients with worsening exercise tolerance at follow-up, DWS was lower at baseline than in the patients with unchanged exercise tolerance. Taken together, these findings indicate that EVAR increased the stiffness of the arteries and heart, limited performance, and generated clinical symptoms.

Among our cohort of Japanese patients, EVAR raised baPWV within 1 week of the operation without elevation of BP. The observed increase in baPWV indicates that aortic vascular stiffness was elevated as a result of the procedure. ${ }^{19}$ Previous studies have reported that AAA patients show reduced vascular compliance at the level of the aneurysmal sac after EVAR, ${ }^{6-8}$ but these studies collected data for vascular compliance just after and at 3 months after the operation. Our data collected expand the findings of these previous studies by revealing that vascular compliance remains impaired for approximately 1 year after EVAR. The EVAR stent graft design, which involves a fabric tube supported by a metal framework, may account for the increase in total aortic vascular stiffness without elevation of BP. This speculation is supported by the high baPWV measured within 1 week of the operation.

In this study, significant increases in LVMI were detected post-op, and the changes in LVMI positively correlated with those in baPWV despite brachial systolic BP being similar between the pre-op and follow-up periods. Several studies have shown that arterial stiffness is associated with LV hypertrophy, ${ }^{20-22}$ and that central arterial stiffness reflects baPWV. ${ }^{23,24}$ Stiffened arteries alter the arterial pressure waveform and also 
lead to increased PWV. These changes result in the reflected wave arriving earlier in the cardiac cycle, thus adding to the central arterial pressure wave to produce augmented central systolic arterial pressure. ${ }^{25}$ Roman et al reported that central arterial pressure is a stronger stimulus for LV hypertrophy than brachial BP. ${ }^{26}$ Thus, a possible explanation for the observed progression of LV hypertrophy without a significant increase in systolic brachial BP after EVAR is that the central aortic pressure is significantly elevated after EVAR. This concept is supported by a study that showed that EVAR increases the velocity of reflected waves. ${ }^{27}$

EVAR increased LAVI at both post-op and follow-up compared with pre-op. LA volume serves as a marker of comprehensive diastolic dysfunction. ${ }^{18}$ A close correlation exists between baPWV and LV diastolic function assessed by echocardiography. ${ }^{28,29}$ This correlation is supported by our present finding that LV relaxation (E') and distensibility (DWS) tended to worsen after EVAR. Among our 22 study patients, 13 had lower SAS scores at follow-up than at pre-op. Interestingly, these patients had larger changes in baPWV and LAVI than the patients with unchanged SAS scores. A clinical investigation has demonstrated that diastolic function and exercise tolerance are closely related. ${ }^{30}$ Kass and Borlaug 9,10 proposed the notion of ventricular-arterial interaction, in which the stiffness of both the heart and arteries interacts to limit performance and generate clinical symptoms. Therefore, the findings from our present study indicate that EVAR may reduce exercise tolerance, at least partially, by increasing vascular stiffness, inducing LV hypertrophy, and deteriorating LV diastolic function. LV diastolic dysfunction is induced not only by LV hypertrophy but also by LV fibrosis and coronary blood flow. The adverse effects of a stiff aorta on LV fibrosis and coronary blood flow are important issues that also need to be investigated. Interestingly, the patients with worsening exercise tolerance had lower DWS at pre-op compared with those with unchanged exercise tolerance, a finding that suggests that patients with poor LV distensibility are likely to have decreased exercise tolerance after EVAR. DWS may become a predictive marker for exercise intolerance after EVAR. However, future prospective studies are needed to confirm this relationship.

\section{Study Limitations}

Several limitations of this study warrant mention. First, the number of study subjects was small, and the number of patients whose data was obtained at follow-up was lower than at preand post-op. Second, as medications were not withheld from study subjects for ethical reasons, it is possible that these medications might have effected the outcomes of LV geometry and diastolic function. Third, the plasma concentration of biomarkers for cardiac dysfunction/heart failure, such as brain natriuretic peptide (BNP) and N-terminal pro-BNP, was not determined. Fourth, all of the study subjects were Japanese. Fifth, the majority of the subjects had AAA and only a few had TAA or TAAA. Finally, baPWV may not be accurate in patients with AAA and TAA. ${ }^{31}$ However, the length of the aortic aneurysm is a relatively small fraction of the distance between the brachial and ankle arteries and measurement of baPWV may not be strongly influenced by aortic aneurysm. This hypothesis is partly explained by the lack of a difference in baPWV between patients with AAA and matched controls. ${ }^{32}$

\section{Conclusions}

In this long-term observational study, EVAR raised aortic vascular stiffness, induced LV hypertrophy, and impaired LV dia- stolic function without an elevation of BP in the short-term, postoperative period among a group of Japanese patients. The increased aortic vascular stiffness and LV hypertrophy and the impairment of LV diastolic function and exercise tolerance were observed 1 year after EVAR. In addition, low LV distensibility at baseline was associated with the impairment of exercise tolerance. Thus, our findings indicate that low LV distensibility at baseline may be related to the impairment of exercise tolerance after EVAR. Taken together, it is necessary to evaluate LV diastolic function and aortic stiffness before and immediately after EVAR to improve the rate of overall survival after EVAR over longer follow-up periods.

\section{Acknowledgments}

The authors are grateful to Ms Yumiko Kobayashi and Ms Keiko Katsuki for technical assistance with the echocardiographic evaluation. This study was supported by grants from the Kimura Memorial Heart Foundation and a Bayer Grant for Clinical Vascular Function.

\section{References}

1. Volodos NL, Shekhanin VE, Karpovich IP, Troian VI, Gur'ev Iu A. [A self-fixing synthetic blood vessel endoprosthesis]. Vestn Khir Im I I Grek 1986; 137: 123-125.

2. Parodi JC, Palmaz JC, Barone HD. Transfemoral intraluminal graft implantation for abdominal aortic aneurysms. Ann Vasc Surg 1991; 5: $491-499$

3. Prinssen M, Verhoeven EL, Buth J, Cuypers PW, van Sambeek MR, Balm R, et al. A randomized trial comparing conventional and endovascular repair of abdominal aortic aneurysms. N Engl J Med 2004; 351: $1607-1618$.

4. Blankensteijn JD, de Jong SE, Prinssen M, van der Ham AC, Buth J, van Sterkenburg SM, et al. Two-year outcomes after conventional or endovascular repair of abdominal aortic aneurysms. $N$ Engl J Med 2005; 352: 2398-2405.

5. De Bruin JL, Baas AF, Buth J, Prinssen M, Verhoeven EL, Cuypers $\mathrm{PW}$, et al. Long-term outcome of open or endovascular repair of abdominal aortic aneurysm. N Engl J Med 2010; 362: 1881-1889.

6. Sekhri AR, Lees WR, Adiseshiah M. Measurement of aortic compliance in abdominal aortic aneurysms before and after open and endoluminal repair: Preliminary results. J Endovasc Ther 2004; 11: 472-482.

7. van Herwaarden JA, Muhs BE, Vincken KL, van Prehn J, Teutelink A, Bartels LW, et al. Aortic compliance following EVAR and the influence of different endografts: Determination using dynamic MRA. $J$ Endovasc Ther 2006; 13: 406-414.

8. Long A, Rouet L, Vitry F, Albertini JN, Marcus C, Clement C. Compliance of abdominal aortic aneurysms before and after stenting with tissue Doppler imaging: Evolution during follow-up and correlation with aneurysm diameter. Ann Vasc Surg 2009; 23: 49-59.

9. Kass DA. Ventricular arterial stiffening: Integrating the pathophysiology. Hypertension 2005; 46: 185-193.

10. Borlaug BA, Kass DA. Ventricular-vascular interaction in heart failure. Heart Fail Clin 2008; 4: 23-36.

11. Imai E, Horio M, Nitta K, Yamagata K, Iseki K, Tsukamoto Y, et al. Modification of the Modification of Diet in Renal Disease (MDRD) study equation for japan. Am J Kidney Dis 2007; 50: 927-937.

12. Sezai A, Soma M, Nakata K, Hata M, Yoshitake I, Wakui S, et al. Comparison of febuxostat and allopurinol for hyperuricemia in cardiac surgery patients (NU-FLASH Trial). Circ J 2013; 77: 2043-2049.

13. Nishio M, Sakata Y, Mano T, Ohtani T, Takeda Y, Hori M, et al. Difference of clinical characteristics between hypertensive patients with and without diastolic heart failure: The roles of diastolic dysfunction and renal insufficiency. Hypertens Res 2008; 31: 1865-1872.

14. Devereux RB, Alonso DR, Lutas EM, Gottilieb GJ, Campo E, Sachs I, et al. Echocardiographic assessment of left ventricular hypertrophy: Comparison to necropsy findings. Am J Cardiol 1986; 57: 450-458.

15. Schiller NB, Shah PM, Crawford M, DeMaria A, Devereux R, Feigenbaum H, et al. Recommendations for quantitation of the left ventricle by two-dimensional echocardiography: American Society of Echocardiography Committee on Standards, Subcommittee on Quantitation of Two-dimensional Echocardiograms. J Am Soc Echocardiogr 1989; 2: 358-367.

16. Lester SJ, Ryan EW, Schiller NB, Foster E. Best method in clinical practice and in research studies to determine left atrial size. Am J Cardiol 1999; 84: 829-832.

17. Sakata Y, Ohtani T, Takeda Y, Yamamoto K, Mano T. Left ventricu- 
lar stiffening as therapeutic target for heart failure with preserved ejection fraction. Circ J 2013; 77: 886-892.

18. Tsang TS, Barnes ME, Gersh BJ, Bailey KR, Seward JB. Left atrial volume as a morphophysiologic expression of left ventricular diastolic dysfunction and relation to cardiovascular risk burden. Am J Cardiol 2002; 90: 1284-1289.

19. Yamashina A, Tomiyama H, Takeda K, Tsuda H, Arai T, Hirose K, et al. Validity, reproducibility, and clinical significance of noninvasive brachial-ankle pulse wave velocity measurement. Hypertens Res 2002; 25: 359-364.

20. Bouthier JD, De Luca N, Safar ME, Simon AC. Cardiac hypertrophy and arterial distensibility in essential hypertension. Am Heart J 1985; 109: $1345-1352$

21. Isnard RN, Pannier BM, Laurent S, London GM, Diebold B, Safar ME. Pulsatile diameter and elastic modulus of the aortic arch in essential hypertension: A noninvasive study. J Am Coll Cardiol 1989; 13: $399-405$.

22. Roman MJ, Ganau A, Saba PS, Pini R, Pickering TG, Devereux RB. Impact of arterial stiffening on left ventricular structure. Hypertension 2000; 36: 489-494.

23. Sugawara J, Hayashi K, Yokoi T, Cortez-Cooper MY, DeVan AE, Anton MA, et al. Brachial-ankle pulse wave velocity: An index of central arterial stiffness? J Hum Hypertens 2005; 19: 401-406.

24. Tsuchikura S, Shoji T, Kimoto E, Shinohara K, Hatsuda S, Koyama H, et al. Brachial-ankle pulse wave velocity as an index of central arterial stiffness. J Atheroscler Thromb 2010; 17: 658-665.

25. O'Rourke MF, Kelly RP. Wave reflection in the systemic circulation and its implications in ventricular function. J Hypertens 1993; 11:
$327-337$.

26. Roman MJ, Okin PM, Kizer JR, Lee ET, Howard BV, Devereux RB. Relations of central and brachial blood pressure to left ventricular hypertrophy and geometry: The Strong Heart Study. J Hypertens 2010; 28: $384-388$

27. Lantelme P, Dzudie A, Milon H, Bricca G, Legedz L, Chevalier JM, et al. Effect of abdominal aortic grafts on aortic stiffness and central hemodynamics. J Hypertens 2009; 27: 1268-1276.

28. Masugata H, Senda S, Yoshikawa K, Yoshihara Y, Daikuhara H, Ayada Y, et al. Relationships between echocardiographic findings, pulse wave velocity, and carotid atherosclerosis in type 2 diabetic patients. Hypertens Res 2005; 28: 965-971.

29. Wang CP, Hung WC, Yu TH, Hsu HL, Chen YH, Chiu CA, et al. Brachial-ankle pulse wave velocity as an early indicator of left ventricular diastolic function among hypertensive subjects. Clin Exp Hypertens $2009 ; 31: 31-43$.

30. Skaluba SJ, Litwin SE. Mechanisms of exercise intolerance: Insights from tissue Doppler imaging. Circulation 2004; 109: 972-977.

31. Odaira M, Tomiyama H, Matsumoto C, Yoshida M, Shiina K, Nagata $\mathrm{M}$, et al. Strength of relationships of the pulse wave velocity and central hemodynamic indices with the serum N-terminal fragment B-type natriuretic peptide levels in men: A worksite cohort study. Circ J 2012; 76: $1928-1933$.

32. Lee CW, Sung SH, Chen CK, Chen IM, Cheng HM, Yu WC, et al. Measures of carotid-femoral pulse wave velocity and augmentation index are not reliable in patients with abdominal aortic aneurysm. $J$ Hypertens 2013; 31: 1853-1860. 